\title{
An Investigation of the Multiple Correlations between Visual-Perception Skills and the Indices of Wechsler Intelligence Scale for Children with Learning Disabilities
}

\author{
Zahra Amirian \\ Payam-e-Nur University, Isfahan, Iran \\ Email Address: amirianz@ymail.com
}

\author{
Doi:10.5901/mjss.2014.v5n7p542
}

\begin{abstract}
The present study investigated the multiple correlations between visual-perception skills and the indices of Wechsler Intelligence Scale for Children with learning disabilities. The statistical population included third-grade students with learning disabilities in the city of Isfahan, Iran, in 2013-14. 100 students were selected by multistage (cluster random) sampling. The method was correlation analysis, and the Myklebust test, Wechsler Intelligence Scale, and Frostig Developmental Test of Visual Perception were used. Pearson's correlation coefficient and stepwise regression were used to analyze collected. The results of the study revealed a meaningful correlation between a set of visual-perception skills and intelligence indices. The best identifiers of students' intelligence were figure-ground perception, consistency of shape, and position in space $(p \leq 0.01)$.
\end{abstract}

Keywords: third grade; intelligence; learning disability; visual-perception skills.

\section{Introduction}

The term "children with learning disabilities" refers to children with disabilities in one or more of basic psychological processes such as perception, comprehension, and expressive and written language use, which might manifest themselves in listening, reasoning, speaking, reading, writing, spelling, and mathematical calculation (Alizadeh 2004).

These disabilities include perception disorders, brain injury, brain disorders, ineligibility, and developmental dyslexia. This definition does not include children with learning disabilities rooted in visual, auditory, or kinesthetic disabilities, mental retardation, emotional disorders, or environmental, cultural, and financial depravities (Werner 1997).

The following can thus be considered as characterizing children with learning disabilities; however, it must be noted that a set of these characteristic are required for children to be diagnosed with such disabilities:

Low educational performance; dysfunctional short-term memory; language disorders including those in internal language, receptive language, word recognition, expressive language, verbal memory; and reading disorders including those in phonological processing, word recognition and decoding (Ilvard and Brown 1998).

Such children typically give irrelevant responses in discussions, use their fingers in calculation, and show deficient attention, clumsiness, low self-confidence, eye-motor problems, and motor dysfunctions. Moreover, they might feature signs of disorders in orientation and time-space perception and estimation as well as the ability to concentrate on details (Nelson et al. 1996).

Learning disabilities are considered as brain-related neurological or language-processing impairment by mental health and medical professionals. One result of such brain disorder is abnormal information processing. A learning disability in education might be related to word recognition, reading comprehension, calculation, reasoning, spelling, or word combination; such disabilities are also often associated with speech disorders. A learning disability in education might as well cause disorders on other levels such as daily activities and household chores due to deficient working memory, reasoning or problem solving originated from neurological causes. Social relationships might also be affected since problematic cognitive performance can lead to misbehavior and misunderstanding. Consequently, learning disabilities can cause depression and anxiety. However, such disorders are neither identical to learning disabilities nor emotional disorders (Wallace et al. 1994).

Various brain disorders associated with learning disabilities are yet to be further explored and classified in terms of causes and progression. For instance, ineligibility is among learning disabilities and affects the reading process and spelling. Studies have shown that abnormal brain performance in auditory-lingual processes (e.g. automatic naming) are shared by many people with ineligibility (Gartland et al. 2007).

There is evidence that suggest that automatic and rapid naming and phonological awareness are fundamental 
processes that identify reading skills (McLean \& Hictch 2001). People, it must be noted, have different visual-perception structures; nonetheless, visual-specific deficiencies might extend into other skills (Sachse-Lee \& Swanson 2001). Different studies are being carried that that show various brain disorders are responsible for learning disabilities (Kirk \& Chalfant 1998).

The need to reevaluate the criteria for the diagnosis of learning disabilities changes alongside educational policies and new findings. Nonetheless, it is unanimously agreed that brain disorders underlie learning disabilities. Therefore, anyone with abnormal performance at school or in everyday life is suspect of suffering from learning disabilities and need neurological examinations to show which brain functions fall under average performance (Kakavand 2010). Neurological examinations cover the required range of evaluations for discussions of learning disabilities such as sensory-kinesthetic performance. The wide range of evaluations obtained by neurological examinations make it possible to identify points of weakness and strength, both of which are necessary for any intervention (Fletcher et al. 2009).

Learning disabilities are chronic and lifetime, possibly affecting emotional, educational, professional performance and thus having implications for interpersonal relationships and society on the large scale. Children with learning disabilities have unsatisfactory performance at school and are unlikely to finish high school. Learning disabilities can have negative effects on one's career at older ages. Therefore, early diagnosis can facilitate treatment and special educational and professional plans (Shokouhiyekta and Parand 2006).

As can be expected, the question of children with learning disabilities has always haunted researchers. The first serious step was taken during the last years of the 1930s and the beginning of the 1940s by the psychologist Werner and his neuro-psychiatrist assistant Strauss (Lerner 2000).

Learning disabilities present the most serious challenges for special education. Learners with disabilities suffer from hopelessness and feel like a failure all the time. The wider the gap between their potentials and achievements, the more serious damage to their personality. In addition to these signs, children with learning disabilities can be distinguished from other special children based on the facts that they usually:

1. have average or above average intelligence.

2. have normal sensory (visual, auditory, etc.) abilities.

3. have appropriate educational and environmental facilities.

4. do not exhibit sever behavioral disorders.

5. are marked by significant discrepancy between their educational performance and intelligence, age, and available facilities (Sayyah-Sayyari 2007).

Studies have shown that 6.4 percent of the children population suffer from learning disabilities and require interventional programs (Abedi 2008). Some scientists believe that coordination in motor skills form the basis for learning abilities. Certain children with special learning disabilities show significantly lower motor development in comparison to normal children (Tabrizi 2010). Children with visual perception and recognition difficulties (visual agnosia) suffer from visual impairment despite their normal eyesight and perception skills. Similarly, children with auditory agnosia have problems in identifying similarities and differences in words in spite of their normal auditory skills (Seyf-Naraqi, Naderi 2003).

A number of researches including Seidman, Biderman, Doyle \& Faran (2001), Seidman (2006), Swanson et al. (2006), and Swanson and Jerman (2007) have shown that children with learning disabilities have lower performance in comparison with normal children in achievement, learning, and attention tests. Other studies have also pointed out that neurological deficiencies such as performance and attention disorders in pre-primary school children continue to exist at later ages and challenge the children in doing homework and personal tasks. Therefore. It is crucial that these disorders be diagnosed as soon as possible and intervention programs be carried out.

Taking into account the above issues and findings, the present study undertook to investigate the multiple correlations between visual-perception skills and the indices of Wechsler Intelligence Scale for Children with learning disabilities in third-grade students.

\section{Method}

The method used is correlation analysis. The statistical population included third-grade students with learning disabilities in the city of Isfahan, Iran, in 2013-14, out of which 100 students were selected by randomly.

\section{Instruments}

The following instruments were used in this study. 
1. The Pupil Rating Scale: Screening for Learning Disabilities. The scale consists of 24 questions and was designed in 1969 and revised in 1981 by Myklebust to identify students with learning disabilities. The scale rates students in terms of five parameters:

- Auditory comprehension

- Spoken language

- Orientation

- Motor coordination

- Personal-social behavior

The rating is on a 1-5 scale with 3 as average, 1 and 2 as below average, and 4 and 5 as above average scales. The scale obtains verbal, nonverbal, and overall scores. The verbal score is the sum of the scores for auditory comprehension, spoken language, and orientation; the nonverbal scores sums up the scores for motor coordination and personal-social behavior; and the overall score equals the sum of the previous two scores. The scale then assesses both verbal and nonverbal abilities of the students.

Myklebust's 1969 five-year-long research project on 2176 children showed that the teacher's judgment in identifying children with learning disabilities were more reliable than neurological, psychological, and EEG tests. The highest score in the scale is 120, with 81 and 61 as the average scores for, respectively, normal children and children with learning disabilities.

2. Wechsler Intelligence Scale for Children WISC-R. to assess the students' intelligence, the Wechsler Intelligence Scale for Children translated into Persian, adapted, and standardized by Shahim (2006) for children aged 6-13 in Shiraz was used. Shahim's study reported a validity of \%44-99.

3. Frostig Developmental Test of Visual Perception. The Frostig Developmental Test of Visual Perception was presented in 1963. The scale was the result of a study on 2116 children selected randomly from kindergartens and first through third grades. The results showed a correlation coefficient of $\% 40-50$ between the scale scores and reading development in a typical first grade. The Frostig scale measures the following five skills:

- eye-motor coordination

- figure-ground perception

- constancy of shape

- position in space

- and spatial relations

The present study considered all the five subtests.

\section{Method of Statistical Analytical}

To analyze the multiple correlations between visual-perception variables and intelligence indices Pearson's correlation coefficient stepwise regression analysis were used. All the statistical analyses were done by SPSS-19. The predictor variables were the visual-perception variable and its sub-indices and the Wechsler Intelligence scale and its sub-indices.

\section{Results}

5.1 Hypothesis 1: There is a correlation between visual-perception skills and verbal intelligence.

Table (1): Correlation Coefficient between Visual-Perception Skills and Wechsler Verbal Intelligence

\begin{tabular}{|l|c|c|c|}
\hline \multicolumn{2}{|c|}{ Independent Variable Wechsler Verbal Intelligence } \\
\hline \multicolumn{1}{|c|}{ Statistical Index } & Correlation Coefficient & The Square of Correlation Coefficient & The level of Significance \\
\hline The eye-motor Coordination & $0.289^{\star \star}$ & 0.084 & 0.004 \\
\hline Figure-ground Perception & $0.872^{\star \star}$ & 0.760 & 0.001 \\
\hline Constancy of Shape & $0.553^{\star \star}$ & 0.306 & 0.001 \\
\hline Position in Space & $0.287^{\star \star}$ & 0.082 & 0.004 \\
\hline Spatial Relation & -0.008 & 0.000 & 0.938 \\
\hline Overall Perceptual- Visual Skills & $0.763^{\star \star}$ & 0.582 & 0.001 \\
\hline
\end{tabular}

$\mathrm{P}<0 / 01$ 
As Table 1 shows, the correlation coefficient between verbal intelligence on the one hand and eye-motor coordination, figure-ground perception, constancy of form, position in space, and the overall visual-perception skills score on the other hand is meaningful. No meaningful relationship was observed between spatial relations and verbal intelligence.

\subsection{Hypothesis 2: There is a correlation between visual-perception skills and nonverbal intelligence.}

Table (2): Correlation Coefficient between Perceptual- Visual Skills and Nonverbal Intelligent

\begin{tabular}{|l|c|c|c|}
\hline \multicolumn{2}{|c|}{ Independent Variable Non- Verbal Intelligence } \\
\hline $\begin{array}{c}\text { Stastical Index } \\
\text { Predictive Varlabtes }\end{array}$ & Correlation Coefficient & The Square of Correlation Coefficient & The level of Significance \\
\hline The eye-motor Coordination & -0.025 & 0.000 & 0.807 \\
\hline Figure-ground Perception & $0.573^{\star \star}$ & 0.328 & 0.001 \\
\hline Constancy of Shape & 0.067 & 0.004 & 0.506 \\
\hline Position in Space & $0.247^{\star \star}$ & 0.061 & 0.013 \\
\hline Spatial Relation & 0.039 & 0.001 & 0.697 \\
\hline Overall Perceptual- Visual Skills & $0.334^{\star \star}$ & 0.112 & 0.001 \\
\hline
\end{tabular}

$$
\mathrm{P}<0 / 05
$$

As can be seen in Table 2, the correlation coefficient between nonverbal intelligence on the one hand and figure-ground perception, position in space, and the overall visual-perception skills score on the other hand is meaningful. No meaningful relationship was observed between eye-motor coordination, constancy of form, and spatial relations and verbal intelligence.

\subsection{Hypothesis 3: There is a correlation between visual-perception skills and overall intelligence.}

Table (3): Correlation Coefficient between Perceptual- Visual Skills and Overall Intelligence

\begin{tabular}{|c|c|c|c|}
\hline \multicolumn{4}{|c|}{ Independent Variable Overall Intelligence } \\
\hline $\begin{array}{c}\text { Statistical Index } \\
\text { Predictive Variabtes }\end{array}$ & Correlation Coefficient & The Square of Correlation Coefficient & The level of Significance \\
\hline The eye-motor Coordination & 0.190 & 0.0361 & 0.058 \\
\hline Figure-ground Perception & $0.892^{\star \star}$ & 0.796 & 0.001 \\
\hline Constancy of Shape & $0.420^{\star *}$ & 0.176 & 0.001 \\
\hline Position in Space & $0.322^{* \star}$ & 0.104 & 0.001 \\
\hline Spatial Relation & 0.014 & 0.000 & 0.891 \\
\hline Overall Perceptual- Visual Skills & $0.698^{\star \star}$ & 0.487 & 0.001 \\
\hline
\end{tabular}

As Table 3 shows, the correlation coefficient between overall intelligence on the one hand and figure-ground perception, constancy of form, position in space, and the overall visual-perception skills score on the other hand is meaningful. No meaningful relationship was observed between eye-motor coordination, and spatial relations and verbal intelligence.

\subsection{Hypothesis 4: Visual-perception skills can predict students' intelligence.}

Table (4): Multiple Correlation Coefficient of Perceptual- Visual Skills in Predicting Intelligence Variable.

\begin{tabular}{|c|c|c|c|c|c|c|c|}
\hline \multicolumn{2}{|c|}{$\begin{array}{c}\text { Statistical Index } \\
\text { Independent Varlable }\end{array}$} & Predictive variable & $\begin{array}{c}\text { Multiple } \\
\text { Correlation } \\
\text { Coefficient }\end{array}$ & $\begin{array}{c}\text { The Square of } \\
\text { Multiple Correlation } \\
\text { Coefficient }\end{array}$ & $\begin{array}{c}\text { The Scaled Square of } \\
\text { Multiple Correlation } \\
\text { Coefficient }\end{array}$ & $\begin{array}{c}\text { F- } \\
\text { Coefficient }\end{array}$ & $\begin{array}{l}\text { The level of } \\
\text { significance }\end{array}$ \\
\hline \multirow{3}{*}{$\begin{array}{c}\text { Overall } \\
\text { Intelligence }\end{array}$} & Frist Step & $\begin{array}{l}\text { Figure-ground } \\
\text { Perception }\end{array}$ & 0.892 & 0.795 & 0.793 & 379.682 & 0.001 \\
\hline & $\begin{array}{l}\text { Second } \\
\text { Step }\end{array}$ & $\begin{array}{c}\text { Figure-ground } \\
\text { Perception } \\
\text { Constancy of Shape }\end{array}$ & 0.916 & 0.838 & 0.835 & 251.465 & 0.001 \\
\hline & Third Step & $\begin{array}{l}\text { Figure-ground } \\
\text { Perception } \\
\text { Constancy of Shape } \\
\text { Position in Space }\end{array}$ & 0.923 & 0.851 & 0.846 & 182.981 & 0.001 \\
\hline
\end{tabular}


As is shown by Table 4, the regression analysis showed that the best predictor of the students' intelligence were figureground perception in the first step and figure-ground perception, constancy of form, and position in space in the second step of analysis. Stepwise regression analysis showed a meaningful relationship between intelligence and figure-ground perception, constancy of form, and position in space indices. Accordingly, in the first step figure-ground perception explained \%89.2, in the second step figure-ground perception and constancy of form explained \%91.6, and in the third step figure-ground perception, constancy of form, and position in space explained $\% 92.3$ of the variance in the students' intelligence. The significance level of $p<0.01$ for observed $F$ shows that the results can be generalized for the statistical population.

Table (5): The Table of $\beta$ - Coefficient in Predicting Student's Intelligent

\begin{tabular}{|c|c|c|c|c|c|c|}
\hline \multicolumn{2}{|c|}{$\begin{array}{c}\text { Statistical Index } \\
\text { Independent Variable }\end{array}$} & Predictive variable & $\begin{array}{c}\text { Non- standardized } \beta \text { Coefficients } \\
\beta \text { Standard Deviation } \\
\end{array}$ & $\begin{array}{l}\text { Standardized } \\
\text { B- Coefficients }\end{array}$ & t- Coefficient & $\begin{array}{l}\text { The level of } \\
\text { significance }\end{array}$ \\
\hline \multirow{3}{*}{$\begin{array}{c}\text { General } \\
\text { Intelligence }\end{array}$} & Frist Step & Figure-ground Perception & 2.4150 .124 & 0.892 & 19.485 & 0.001 \\
\hline & Second Step & $\begin{array}{c}\text { Figure-ground Perception } \\
\text { Constancy of Shape }\end{array}$ & $\begin{array}{l}2.5380 .113 \\
1.5500 .304\end{array}$ & $\begin{array}{l}0.937 \\
0.213\end{array}$ & $\begin{array}{c}22.424 \\
5.107\end{array}$ & $\begin{array}{l}0.001 \\
0.001\end{array}$ \\
\hline & Third Step & $\begin{array}{c}\text { Figure-ground Perception } \\
\text { Constancy of Shape } \\
\text { Position in Space }\end{array}$ & $\begin{array}{l}2.5120 .110 \\
1.4020 .297 \\
0.4470 .156 \\
\end{array}$ & $\begin{array}{l}0.927 \\
0.193 \\
0.115\end{array}$ & $\begin{array}{c}22.923 \\
4.718 \\
2.877 \\
\end{array}$ & $\begin{array}{l}0.001 \\
0.001 \\
0.005\end{array}$ \\
\hline
\end{tabular}

Table 5 shows that the beta coefficient reveals $0.927,0.193$, and 0.115 standard deviations increase in the students' intelligence per respectively a standard deviation increase in figure-ground perception, constancy of form, and position in space.

The prediction equation for Hypothesis 4 can be thus formulated:

Intelligence $=9.956$ standardized coefficient +22.923 figure-ground perception +4.718 constancy of form +2.877 position in space.

\section{Results and Discussion}

The results of the study showed the existence of a meaningful correlation coefficient between eye-motor coordination, figure-ground perception, constancy of form, position in space, and the overall score for visual-perception skills on the one hand and verbal and overall intelligence on the other and also a meaningful correlation coefficient between figureground perception, position in space, and overall visual-perception skills on the one hand and nonverbal intelligence on the other.

The findings of the present study are in line with those of Seidman, Biederman, Doyle, and Faraone (2001), Semrud-Clikeman et al. (1992), Swanson et al. (2006), and Swanson and Jerman (2007). Swanson, Ashbaker, and Lee (2000 qtd. In Abedi 2008) investigated the different implications of working memory on students' learning. They also studies information storage in working memory and short-term memory. The results of their study showed that children with reading disabilities have below average performance in storing information in spatial-visual memory and short-term memory. The researchers found out that there was a meaningful direct relationship between the children's intelligence and their perception skills.

From these results it can be argued that, to improve the intelligence of children with learning disabilities, special assignments must be designed to improve their visual-perception skills.

The effect of instructions on learning has been proved. These instructions are important in improving students' visual perception and learning processes. In fact, direct instructions can be said to play a crucial role in helping these students. Such instructions can be beneficial to all students, especially to those with learning disabilities. Most children follow such directions automatically, but children with learning disabilities need to be taught.

Based on these results it can be argued that many learning difficulties and low intelligence level derive from a lack of skills, and that the instruction of these skills and how to use them is the crucial issue often neglected.

All in all, it can be concluded that the instruction and improvement of skills can be considered in intervention programs for learning disabilities. 


\section{References}

Abedi, Ahmad. (1387). The Standardization of the neuropsychological test of NEPSY in Isfahan. Diss. Esfahan University.

Aylward, Elizabeth H., and Frank R Brown. (1377). Diagnosis and Management of Learning Disabilities: An Interdisciplinary Approach. Trans Reza Baradari. Tehran: The Educational system for Exceptional Students Publication.

Alizadeh, Hamid. (1383). Attention deficit hyperactivity disorder. Tehran. Roshd Publication.

Fletcher, J. M., G. R. Lyon, L. S Fuchs, and M. A Barnes. (2009). Learning Disabilities from Identification to Intervention. New York: Guilford Press.

Frostig, Marianne. (1375). Frostig Developmental Test of Visual Perception. Trans. Mostafa Tabrizi and Masoumeh Mousavi. Tehran: Fararvan Publication.

Gartland, D., and R Stronsnider. (2007). Learning Disabilities and Young Children Identification and Intervention. Learning Disability Quarterly. 30(1): 63-72.

Kakavand, Alireza. (1389). Learning Disabilities. Karaj: Sar-afraz Publication.

Karimi, Yusef. (1389). Learning Disorder. Tehran: Savalan Publication.

Kirk, Samuel A., and James C. Chalfant. (1377). Academic and Developmental Learning Disabilities. Trans. Simin Ronaghi, et al. Tehran: The Educational system for Exceptional Students Publication.

Lerner, Janet. (1379). Learning Disabilities. Trans. Akbar Faryar and Fereidoun Rakhshar. Tehran: Mabna Publication.

Mclean. K. and J Hitch. (2001). Executive Functions in Student with and without Mathematics Disorder. Journal of Learning Disabilities. 30: 214-225.

Nelson, Rita-Wicks, and Allen C Israel. (1375). Behavior Disorder of Childhood. Trans. Taghi Monshi Tousi. Mashhad: Ghods Razavi Publication.

Sachse, lee C and H.L. Swanson. (2001). Mathematical Problem Solving and Working Memory in Children with Learning Disabilities: Both Executive and Phonological Processes Are Important. Journal of Exceptional Children's. 79(3):294- 321.

Sayah Sayari, Nimtaj. (1386). Learning Disability. Tehran: Modabber Publication.

Seidman, L. J. (2006). Neuropsychological Functioning In People with ADHD across the Lifespan. Clinical Psychology Review. 26: $466-$ 485.

Seidman, LJ. , J Biederman, AE Doyle, and Sv Faraone. (2001). Learning Disabilities and Executive Functions in Boys with ADHD. Journal of Neuropsychology. 15(4): 455-56.

Seif Naraghi, Maryam, and Ezat Allah Naderi. (1382). Learning Disorder. Tehran: Amirkabir Publication.

Semrud- Clikeman, M. (2005). Neuropsychological Aspects for Evaluating Disabilities. Journal of Learning Disabilities. 38: 563-568.

Shahim, Sima. (1385). The Revised Wechsler Intelligence Scale for Children: instructions and norms. Shiraz: Shiraz University Publication.

Shokohi Yekta, Mohsen, and Akram Parand. (1385). Learning Disability. Tehran: Teimour Zadeh Publication.

Swanson, L. H., and O Jerman. (2007). The influence of Working Memory of Reading Growth in Subgroups of Children with Reading Disabilities. Journal of Exceptional Child Psychology. 96(4): 249-283.

Swanson, L. H., Saez, L., \& Gerber, M. (2006). Growth in Literacy and Cognition in Bilingual Children at Risk or Not at Risk for Reading Disabilities. Journal of Educational Psychology. 98(2): 247-250.

Tabrizi, Mostafa. (1389). Reading Disorder Treatment. Tehran: Fararvan Publication.

Wallace, Gerald, and James A McLoughlin. (1373). Learning Disabilities: Concepts and Characteristics. Trans. Taghi Monshi Tousi. Mashhad: Ghods Razavi Publication.

Werner, Peter. H. and Lisa Rini. (1376). Perceptual-Motor Development Equipment: Inexpensive Ideas And Activities. Trans. Ali Hossein Sazmand and Seyed Mehdi Tabatabayi. Tehran: The Educational System for Exceptional Students Publication. 